\title{
ESTIMATION METHOD FOR PORT CARGO DEMANDS AFTER LARGE-SCALE EARTHQUAKES AND TSUNAMIS
}

\author{
Yasuhiro AKAKURA ${ }^{1}$ and Kenji $\mathrm{ONO}^{2}$ \\ ${ }^{1}$ Member of JSCE, Port and Harbor Dept., National Institute for Land and Infrastructure Management, MLIT \\ (3-1-1, Nagase, Yokosuka, Kanagawa 239-0826, Japan) \\ E-mail: akakura-y83ab@mlit.go.jp \\ ${ }^{2}$ Member of JSCE, Professor, Disaster Prevention Research Institute, University of Kyoto \\ (Gokasho, Uji, Kyoto 611-0011, Japan) \\ E-mail: ono.kenji.5z@kyoto-u.ac.jp
}

\begin{abstract}
Ports are among the most essential infrastructures for international and domestic trades. Since Japan is an island country, its major ports are requested to prepare business continuity plans (BCPs) to facilitate early recovery of port functions in the context of maintaining the local and national economy. Major objectives of the BCPs in ports include maintaining sufficient cargo handling capacity to meet the transportation demands, of which post-disaster forecast is essential to properly secure business continuity in the port.

Based on the above consideration, this study discusses the possible development of demand estimation methods for port cargo handling volumes in the aftermath of large-scale disasters. The questionnaire/ interview and inventory analysis are suitable for undertaking the estimation in terms of tramper service cargos such as dry/liquid bulk cargos and complete cars, of which a limited number of cargo owners are involved. The statistical approaches are effective for the estimation of liner service cargos such as container and ferry transport, which involve a large and unspecified number of cargo owners. Theoretical concepts, specific examples and considerations of suggested methods are indicated. The authors deem that these discussions may pave the way to the introduction of further sophisticated methodologies for port-BCP preparation.
\end{abstract}

Key Words : business continuity plan, cargo demand, operating ratio, liner, tramper

\section{INTRODUCTION}

Ports are important nodes between water and land surface transportations and are therefore, among the most essential infrastructures for international and domestic trades. Since Japan is an island country, its major ports are requested to prepare business continuity plans (BCPs) to facilitate early recovery of port functions in the context of properly maintaining the local and national economy. Major objectives of the BCPs in ports (port-BCP) include maintaining sufficient cargo handling capacity to meet the transportation demands, of which post-disaster forecast is essential to properly secure business continuity in the port.

Based on the above consideration, this study discusses the possible development of demand estimation methods of port cargos in the aftermath of large-scale disasters.

\section{IMPACT OF PORT DAMAGE}

The South Hyogo Prefecture earthquake in 1995 (known as the Great Hanshin-Awaji Earthquake) completely destroyed container terminals in the Kobe port, rehabilitation works for which took almost two years. In the meanwhile, however, the neighboring ports, such as the Osaka port, failed to fully cover for the Kobe port, resulting in container cargos being shifted to other Asian container hub-ports including Busan Port.

Fig.1 demonstrates the transitions of Kobe port container cargo throughputs, which has shown a great decrease in Japanese local container throughput after the Great Hanshin-Awaji Earthquake. This decrease brought down a shrinkage of container shipping network at Kobe port and, as a result, caused a reducing trend of international transship container ("T/S" in Fig.1) throughput. The Great East Japan 


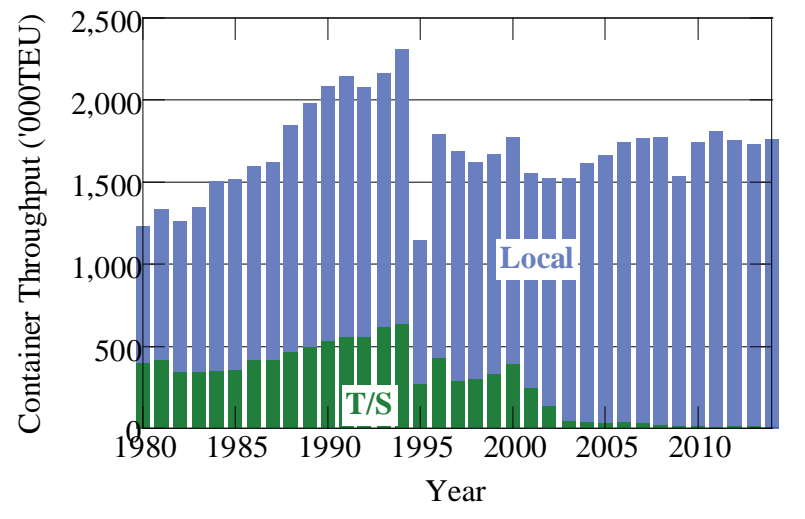

Fig.1 Container throughput and ratio of international transshipment at Kobe port.

Earthquake in 2011 also seriously damaged the Tohoku Pacific Ocean ports of Japan, such as the ports of Sendai-Shiogama, Hachinohe, Onahama, and Kashima. The Takasago container terminal in the Sendai-Shiogama port took two years to be fully rehabilitated. In the meantime, the port relied on the alternative port functions of Tokyo and Yokohama in Tokyo Bay for handling international container and bulk cargos. The Japan Sea side ports such as the ports of Niigata, Sakata, and Akita also assisted the disaster-stricken port in providing alternative cargo handling services. Nevertheless, these ports could not fully meet the cargo handling requirements, resulting in the stagnation of local industrial productions. Fig.2 shows the negative impact on the production activities of port user establishments due to the port function stagnation after the Great East Japan Earthquake. The figure was prepared by the authors based on the questionnaire survey data provided by the Tohoku Regional Development Bureau of the Ministry of Land, Infrastructure Transport and Tourism (MLIT). Fifty-five percent of establishments responded "very large" or "large," hence were likely to be seriously affected by the port function stagnation. The consequences of this stagnation are demonstrated in Fig.3, which indicates a considerably large negative impact on the local production activities, including production cut/shutdown and business opportunity losses.

In the context of the abovementioned negative impact on the port activities and local economy, the Disaster Management Working Group of the Port Sub-committee of Transport Policy Council, MLIT, prepared a policy recommendation to the minister entitled "Earthquake and tsunami risk management policy in ports - For securing lifeline of island nation, Japan.” The recommendation put a particular emphasis on the significance of developing port-BCPs, which were expected to improve the capacity of the ports to respond to disasters. Furthermore, the government enacted the Act for National

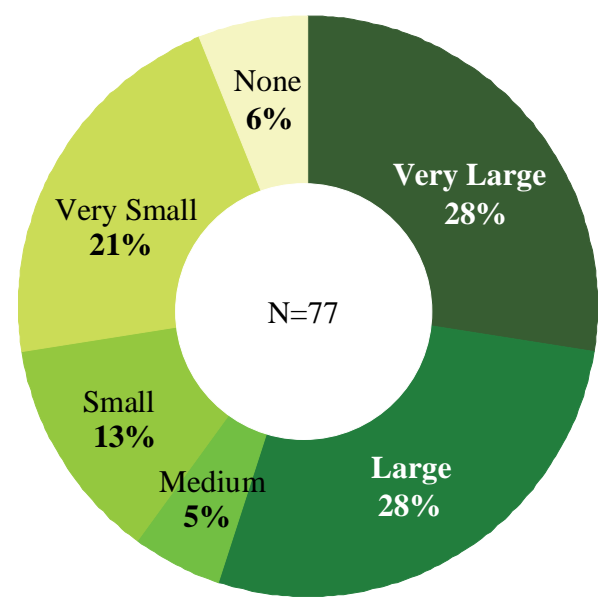

Date: Nov. 24 to Dec. 28, 2011

Target: Port User at Tohoku Pacific Region

Fig.2 Impact of stagnation of port logistic function after Great East Japan Earthquake.

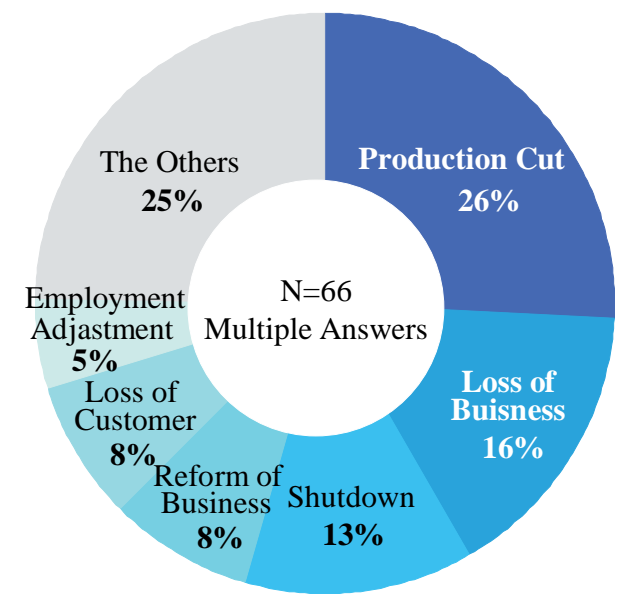

Fig.3 Impact categories of stagnation of port logistic function.

Resilience in December 2013 to improve the resiliency of the national territory in coping with possible occurrence of the Tokyo Inland Earthquake and Nankai Trough Great Earthquake. The government also prepared under the Act, the Improvement Action Plan to facilitate implementation of sector-wise programs with key performance indicators (KPIs) for monitoring the implementation progress. In the area of port sub-sector, the Plan includes a BCP development targeting major Japanese ports to prevent disruption of national trunk logistics network: i.e., raising the development ratio of port-BCPs from 3\% in 2012 to $100 \%$ in 2016. Fig.4 shows the locations of major ports and earthquake-stricken areas. 


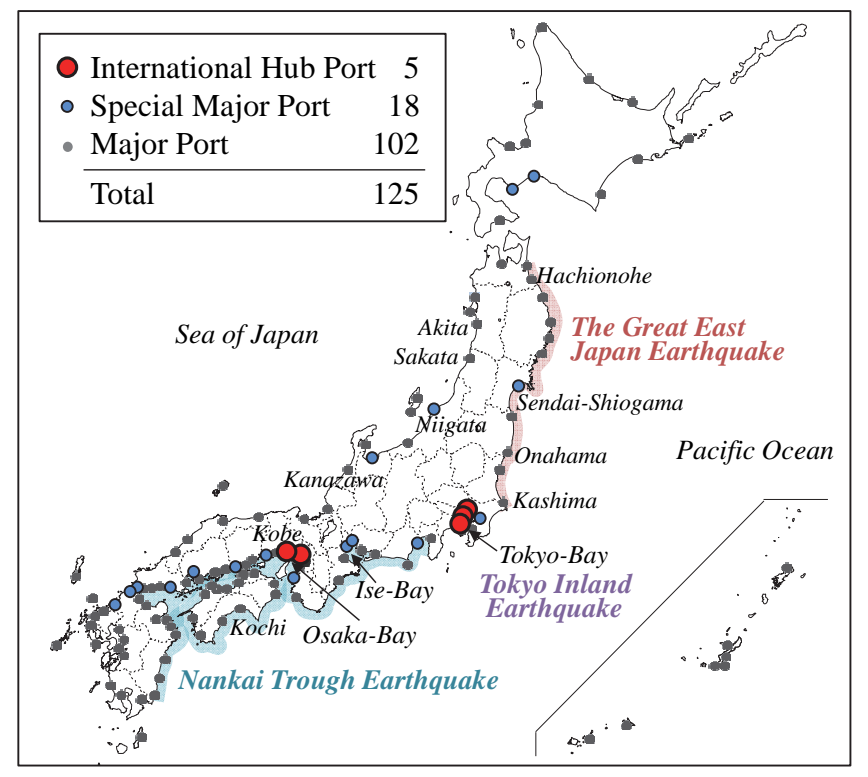

Fig.4 Ports in Japan.

\section{SUPPLY-DEMAND RELATION IN PORT-BCP}

\section{(1) Standards and guidelines of BCP}

Based on a lesson learned from the September 11 attack, the American National Standard Institute initiated a discussion on the standardization of national security at ISO, which issued "ISO22301: Social security - Business continuity management systems - Requirements” in 2012. The new international standard provides a broad-based framework of the business continuity management system (BCMS) to cope with a wide range of critical and emergency situations including large-scale disasters, based on the experiences of the 2004 Indian Ocean earthquake and tsunami and the 2005 Hurricane Catrina storm surge $^{1)}$.

In Japan, the Cabinet office published a Business Continuity Guidelines $1^{\text {st }}$ edition in 2005, which was amended in 2009 after considering the 2009 flu pandemic, and again in 2013 based on the occurrence of the Great East Japan Earthquake. In terms of business continuity at ports, MLIT issued in 2015 "Guidelines for Preparing Business Continuity Plans at Ports (Port-BCP Guidelines).”

ISO22301 requests, for the purpose of selecting and determining the business continuity strategy, that prioritized timeframes be set for resuming business activities at a specified minimum acceptable level, taking into consideration the time within which the impact of not resuming the provision of products and services would become unacceptable. This evaluation process is defined as a business impact analysis (BIA). BIA provides information on the maximum tolerable time period of the clients against the dis- ruption, based on which BCP defines the required resumption timing of the business operation.

\section{(2) Framework of port-BCP}

ISO22301 implicitly assumes that BCP executing organizations are entities with a single management system; however, ports may be defined as an aggregate of a number of port-related public offices and port business entities, including stevedoring companies. There may be an institutional question of who will be the host organization for developing and operating the BCMS at ports.

Main service providers at ports may include port authority (port managing body), stevedoring companies, maritime pilots and CIQ organizations; therefore, strong commitment of these parties are essential to successfully operate the BCMS. Taking into account this fact, the Port-BCP Guidelines requests that "Port-BCP consultative meeting" be set up in the respective port to share information in order to have common business continuity target and risk awareness. Port authority, the local MLIT office, and designated port management companies are expected to participate in the Port-BCP consultative meeting as core members.

\section{(3) Supply-demand relation}

Ports provide cargo owners and shipping companies with logistics services such as cargo loading/unloading, storage, delivery, CIQ inspections, and trade processing. Thus, cargo owners and shipping companies are targeted clients for business continuity at ports. Fig.5 illustrates a schematic view of demand-supply relationship of port logistics services in the aftermath of large-scale disasters. Right after the outbreak of disaster, port cargo demand, which means demand for cargo transportation at port, greatly decreases due to production and supply chain disruption in the hinterland. The cargo demand generally recovers in association with the resumption of the hinterland economic activities as shown by the blue line in the figure. On the other hand, cargo handling capacity is also lowered by the damage of port facilities, which recover in a stepwise fashion by following the progress of clearance works in port water, emergency rehabilitation of quay structures, and repair of quay cranes as shown by the brown line in the figure.

Port-BCP is a plan for maintaining port clients by providing sufficient logistics services. More specifically, the risk evaluation of the port-BCP is undertaken by comparing $R T O$ (Recovery Time Objective) and $R L O$ (Recovery Level Objective) with PRT (Predicted Recovery Time) and PRL (Predicted Recovery Level) as shown in equation (1). 


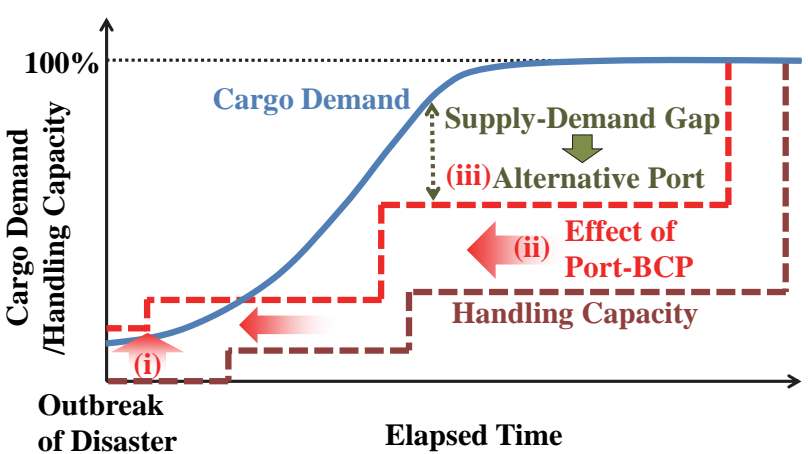

Fig.5 Supply-demand relation of port logistic service.

$R T O / R L O$ are presumed based on the port cargo demand in the aftermath of disasters and PRT/PRL are decided in line with the emergency rehabilitation program of port facilities and are required to satisfy the following condition:

$$
(R T O \geq P R T) \wedge(R L O \leq P R L)
$$

In general, some proactive measures and preparatory works are needed to be undertaken to satisfy the equation. The authors consider the following three categories of risk treatment measures to be discussed to eliminate the supply-demand gap to properly meet the port cargo demand.

i) Increasing robustness of port facilities for maintaining cargo handling capacity in the aftermath of large-scale disasters,

ii) Arranging and preparing for quick repair and rehabilitation works of the facilities including acceleration of procurement procedures for consulting services and civil works, and

iii) Organizing a broad-based alternative port alliance for detouring from disaster-stricken ports in case the abovementioned i) and ii) measures are not enough.

The port-BCP targets to make necessary arrangements and preparation against the expected port traffic disruption by appropriately predicting the possible recovery of cargo owner's demand. In this context, port cargo demand estimation method given by this study may contribute to developing further sophisticated BCP preparation methodology.

\section{(4) Literature review}

Among the past researches in terms of disaster management at ports, Manosouri et al. ${ }^{2)}$ discussed the decision-making procedures of risk management at ports. Miyamoto and $\mathrm{Arai}^{3)}$ undertook pilot works for preparing BCP in the port of Nagoya. Berle et al. ${ }^{4)}$ explained the failure mode of port logistics functions with a view to BCP preparation. Omer et al. ${ }^{5)}$ evaluated the resiliency of port logistics by considering port and shipping network. Abe ${ }^{6)}$ proposed a basic framework of supply and demand relationship of port logistics service in the aftermath of large-scale earthquakes. In terms of negative impact of port shutdown on the national port system in the United States, a study undertaken by Trepte and Rice ${ }^{7)}$ should be referred. Novati et al. ${ }^{8)}$ evaluated the influence of natural and human-made disasters on the port network system. Almost all of the abovementioned past studies did not consider in depth the possible decrease in port traffic demand due to the natural disaster-caused disruptions of local production and supply chain.

Nakano et al. ${ }^{9)}$ and $\mathrm{Abe}^{6)}$ discussed the observed lower operations of local industries in the disaster affected area. There are, however, intervention of inventory and transport lot of goods, and it should be noted that decrease in the production volume is not always directly reflected in the port cargo throughput. Based on the above consideration, this study indicates port cargo demand estimation procedures for liner and tramper cargos, including that of container cargos previously proposed in ref. 10).

\section{ESTIMATION METHODOLOGY OF PORT CARGO DEMAND}

\section{(1) Classification of cargo}

The estimation methods of port cargo demand may be classified into two categories based on the characteristics of cargos as follows:

- Tramper service cargos: A limited number of and mostly specified cargo owners are involved in this vessel transportation category. An example is dry/liquid bulk cargos.

- Liner service cargos: A large number of cargo owners are involved in this vessel transportation category. The shippers share cargo space in a vessel. An example is containerized cargos.

For the tramper service cargos, the handling demands at port directly evaluated based on these cargo owners' production recovery and inventory volume after the disaster. On the other hand, since liner service cargos are aggregations of the demand of many cargo owners, the condition of the respective owners, such as production recovery fades and estimation of post-disaster recovery of the hinterland economy on the average basis is needed. The evaluation method appropriate for each case is indicated in the following sections.

\section{(2) Tramper service cargo}

In the case of tramper service cargos, it is necessary to directly identify the respective cargo handling demands of the shippers at the port. The reason is that each establishment has different cargo transportation 
conditions: inventory volume of products/raw materials, restoration speed of production lines, market demand of the products in the aftermath of the disasters, and so on.

There are two estimation methods for directly identifying the demand, and each method has its merits and demerits.

- Questionnaire and interview survey with establishments: In this method, each establishment is expected to directly answer the restoration speed of port cargo handling demand. The information on possible cargo handling volume to be requested to the port after the disaster, hopefully based on BCP of the company, could be obtained. However, the real intention of the company may not be always revealed. Comments like "the cargo shipment depends on the port function which, therefore, should be restored as soon as possible" are sometimes provided.

- Inventory Analysis: If the restoration speed of the productions and the ordinary inventory volume is identified, the port cargo demand of each establishment can be estimated by considering how long the inventory is intended for. For example, the restoration targets, in the aftermath of the disasters, of lifelines such as electricity and gas are normally publicized by the government, and these data can be utilized for estimating the port cargo handling demand of energy resources.

\section{(3) Liner service cargo}

In the case of liner service cargos, it is substantially impossible to estimate the port cargo handling demand by collecting every shipping volume of the individual cargo owner. The reasons are as follows: (i) there is a great deal of number of the user establishments that are located geographically widely, (ii) the establishments may not have the proper information on the damage caused by future disaster or may not reveal their real information in questionnaire only. From this point of view, the statistical approach, which is based on the data of past disaster, should be employed.

The degree of the disaster damage is generally proportional to the strength of the hazard to some extent. Previous studies such as Nakano et al. ${ }^{9)}$ estimated the impact of a disaster to the operating ratio of each establishment considering this relationship. There is, of course, an influence of the cargo owner's inventory and transportation lot of goods on the relationship between the business operating ratio and the port cargo demand, as discussed before. Therefore, the port cargo demand can be estimated based on the strength of the hazard by quantifying the relationship between the operating ratio and the port cargo handling demand. It is possible to determine the average port cargo demand by quantifying this relation on previous disasters.

Although a large number of cargo owners are normally involved in liner shipping transportation, when the limited number of cargo owners is prominent, the estimation method stated in section (2) can be employed.

\section{ESTIMATION OF TRANSPORT DE- MAND FOR TRAMPER SERVICE CARGOS}

\section{(1) Overview}

The tramper service cargo demand estimation involves a variety of conventional approaches based on indices such as GDP, population, energy consumption, and forecasted volume of production; however, they normally do not need to consider the inventory volumes and the sudden change in demand caused by disasters. In addition, experiences of the estimation for preparing port-BCP in Japan are limited. In this context, this study shows some good practices and case histories with important view points for properly undertaking tramper service cargo demand estimation in the aftermath of the disasters. Among the most common techniques, interview and questionnaire survey examples from the ports of Sakata and Kanazawa are to be referred; as to the inventory analysis, a case history in terms of the fuel oil demand estimation at Kochi port is shown.

The abovementioned port demand estimation methods normally involve two or more external factors, such as the inventory volume and production recovery speed of shippers and the market demand for the products in the aftermath of disasters. The questionnaire and interview survey directly addresses these information at one time, while the inventory analysis requires collecting the respective information accordingly. As an example of market demand evaluation in the aftermath of large-scale disasters, the restoration process of electric power supply is illustrated in Fig.6. The restoration speeds of lifelines are among the most useful information for evaluating energy resource handling demands at ports and are usually available in earthquake damage estimation undertaken by the government and municipalities.

\section{(2) Estimation by questionnaire/interview survey}

Questionnaire/interview survey is often suitable for estimating dry/liquid bulk cargo demand at ports. In the port-BCP ${ }^{11)}$ prepared in Sakata port, an inter view survey with the local establishments was un- 


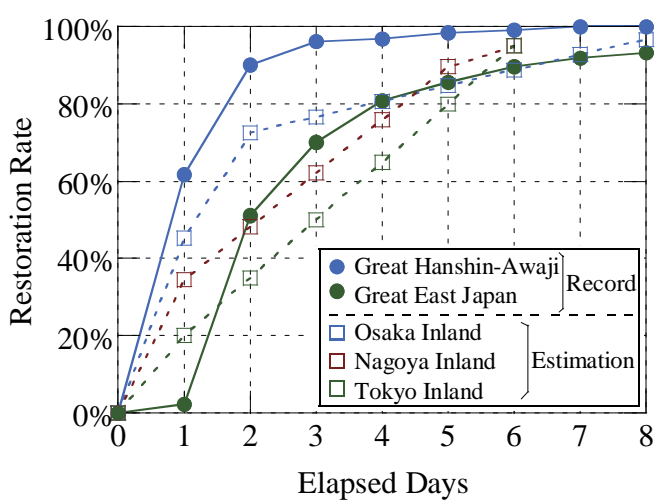

Fig.6 Restoration of electric power supply.

Table 1 Volume of cargo demand and inventory (Sakata).

\begin{tabular}{|c|l|l|}
\hline Cargo & $\begin{array}{c}\text { Cargo Demand } \\
\text { after Outbreak }\end{array}$ & \multicolumn{1}{|c|}{ Volume of Inventory } \\
\hline $\begin{array}{c}\text { Thermal } \\
\text { Coal }\end{array}$ & $\begin{array}{l}1 \text { month }: 50 \% \\
\text { months }: 100 \%\end{array}$ & $\begin{array}{l}40 \text { days (70\% Recover) } \\
1 \text { month (100\% Recover) }\end{array}$ \\
Fuel & 3 days $: 50 \%$ & 2 days \\
Oil & 10 months $: 100 \%$ & \\
\hline
\end{tabular}

dertaken to identify the coal and oil transportation volume, which are major bulk cargos of the port. The survey result is shown in Table $\mathbf{1}$. When the power station in Sakata port sustained a minor damage, it was judged that the cargo handling service for thermal coal in the port had to be resumed one month after the outbreak of the disaster, by considering the inventory volume at the power station. On the other hand, in case the oil terminal operation in Sakata port could not be continued due to disaster damage, it was judged that the fuel oil loading at the port be requested to resume within only three days after the disaster to avoid fuel oil supply shortage in the port hinterland due to the low inventory level of the port. In the Sakata port, namely, inventory volume was calculated to identify the post-disaster transport demand, based on which, the Sakata port-BCP set the target time of restarting cargo handling operation at one month after the outbreak of a disaster for thermal coal and at three days after for fuel oil.

For the port with relatively limited cargo owners, questionnaire/interview survey can be applied to understand the overview of port traffic demands. An example is the BCP preparation in Kanazawa port, where questionnaire/interview survey with twelve cargo owners was conducted and the allowable shutdown time of the port operation after a disaster was decided $^{12}$. Table 2 shows the result of the survey. A half of the cargo owners answered that they would be able to continue operation by mobilizing the inventory one week after the outbreak of a disaster; however, the ratio of operatable cargo owners would decrease in association with the elapsed time. These cargo owners answered that they would shift to
Table 2 Ratio of operatable cargo owner by inventory (Kanazawa).

\begin{tabular}{|c|c|c|c|c|}
\hline $\begin{array}{c}\text { Elapsed Time } \\
\text { after Outbreak }\end{array}$ & $\sim 1$ week & $\sim 2$ Week & $\sim 1$ Month & 1 Month $~$ \\
\hline $\begin{array}{c}\text { Ratio of } \\
\text { Cargo Owners }\end{array}$ & $50 \%$ & $37 \%$ & $18 \%$ & $6 \%$ \\
\hline
\end{tabular}

other ports, continue their business in other areas, or suspend their business. Like this Kanazawa port, it is recommendable to study the detailed situation of each company through interview survey as well as questionnaire survey.

\section{(3) Estimation by inventory analysis}

The result of analysis for the demand estimation of petrol undertaken by the Kochi prefecture ${ }^{13)}$ is introduced as an example of port cargo handling demand estimation based on an inventory analysis approach.

In ordinary time, almost all petrol supplies to the Kochi prefecture are undertaken by oil tankers, which unload the cargos at Tanaska oil station in Kochi port. When the Kochi port becomes unavailable due to the Nankai Trough Earthquake, the petrol supply pipeline for Kochi area immediately disappears. In this case, only the storage petrol is available for distribution to the area. Table $\mathbf{3}$ shows the volume of daily consumption petrol volume in the area and available stock-pile estimated by ref. 13). The timeline is divided into three phases. The Tanaska oil terminal has not recovered yet, therefore is not available for accommodating oil tankers and unloading petrol in all phases. The Kochi city area stores only the volume equivalent to 0.4 days consumption in phase-1; 5.0 days in phase-2. Thus currently, there exists a lack of petrol stockpile volume equivalent to 2.6 days consumption in phase- $1 ; 36$ days in phase-2. A period in Phase- 2 is possibly shortened by taking various countermeasures such as increasing of water stopping and drainage capacity; however, lack in the stock pile cannot be eliminated in both phases even if the long-term plan is completed in more than ten years. Including phase-3, it is, therefore, necessary to develop some strategies to make up for this deficit through Kochi port under the port-BCP. As such, the change in demand in association with various counter measures can be estimated by the detailed inventory analysis.

In the Kochi port-BCP ${ }^{14)}$ developed in March, 2015, the targeted recovery times of access road and the emergency clearance works in the port water around the Tanaska oil terminal (the Ulado gulf) are one week after an earthquake. When these targets are accomplished as scheduled and the handling capacity of the Tanaska oil terminal is also secured, the petrol 
Table 3 Consumption and stock-pile of petrol at Kochi city area after a Nankai Trough Earthquake.

\begin{tabular}{|c|c|c|c|}
\hline Phase & $\begin{array}{c}\text { Phase-1 } \\
\text { Immediately } \\
\text { after Tsunami }\end{array}$ & $\begin{array}{c}\text { Phase-2 } \\
\text { Water Shielding } \\
\text { and Drainage }\end{array}$ & $\begin{array}{c}\text { Phase-3 } \\
\text { Full-Fledged } \\
\text { Restoration }\end{array}$ \\
\hline Daily Demand & $52.3 \mathrm{kl} /$ day & $184.7 \mathrm{kl} /$ day & $237.6 \mathrm{kl} /$ day \\
Stock-Pile & $22.0 \mathrm{kl}$ & $925.9 \mathrm{kl}$ & $0.0 \mathrm{kl}$ \\
Coverable Days & 0.4 days & 5.0 days & 0.0 days \\
\hline Present State & 3 days & 41 days & - \\
Short-Term Plan & 3 days & 23 days & - \\
Mid-Term Plan & 3 days & 10 days & - \\
Long-Term Plan & 3 days & 7 days & - \\
\hline
\end{tabular}

Data from ref. 13)

Phase-1: Immediately after an earthquake. The Kochi city area and the Tanaska oil terminal are flooded All the lifelines stop.

Phase-2: The drainage of Kochi city area start. The Tanaska oil terminal are still flooded.

Phase-3: The drainage of all area is completed. The Tanaska oil terminal cannot function by blackout.

Short/Mid/Long-Term Plan: All plans of countermeasures against tsunami were classified in terms of necessary period;

Short: under 5 y ears, Mid: under 10 y ears, Long: over 10 y ears.

transportation demand after phase-2 is met. In addition, it is possible to start delivering petrol, even if the arrival of oil tanker at the terminal is delayed for a couple of days, because the inventory of the Tanaska oil station can usually accommodate the four days demand. However, there are risks of taking a longer time to complete the water clearance works than those targeted due to a much larger number of debris and floating wreckages caused by a tsunami in the Ulado gulf, where the Tanaska oil terminal is located. There is also a possibility that the handling facilities of the terminal are damaged seriously and the restoration of these facilities take a long time. To cope with these cases, two alternative routes were planned : i) to unload petrol at ports in the neighboring prefectures and to transport long distance with transmountain by road; or ii) to use the general cargo terminal at Kochi new port, which is located out of the Ulado gulf, and to transport to the Kochi city area by road ${ }^{13)}$. It needs to be noted that the recovery of petrol transportation demand may be accelerated if the phase-3 situation is moved earlier by various countermeasures, including tsunami damage mitigation measures.

\section{ESTIMATION OF TRANSPORT DE- MAND FOR LINER SERVICE CARGO}

\section{(1) Overview}

A statistical approach is suitable for the estimation of liner service cargo demands. In this chapter, the estimation methods for the transport demands of the container and the ferry cargo are developed based on the data of the Great East Japan Earthquake.

Among the liner service cargos, container cargo mainly originates from economic activities; therefore, the transport demand depends upon the recovery pace of the establishments' activities. Contrastingly, ferry cargo is largely shared by agricultural and living-related cargos whose transport demand does not greatly decrease in the aftermath of disasters. Furthermore, transporting of emergency relief supplies and dispatching of rescue parties such as the Self-Defense Force cause additional demand for ferry services. Under the circumstances mentioned above, it is suggested that the recovery speed of ferry cargo demands is faster than that of container cargo, on the average.

\section{(2) Estimation of container cargo demand}

The authors had formulated the recovery curves of the container cargo demand in the aftermath of large-scale earthquakes and tsunamis ${ }^{10}$. These recovery curves were formulated based on the questionnaire survey with disaster-stricken establishments as to the operating ratio and the relation between the operating ratios and the transport demands. For more details, please see ref. 10). Table 4 shows the average of the operating ratio of establish ments in terms of the tsunami inundation depth and the JMA (Japan Meteorological Agency) seismic intensity. It should be noted that the operating ratio contains the influence of indirect factors, such as the supply chain disruption and damage to lifeline or transport infrastructures. The operating ratio of establishments at seismic intensities 4 and 5- mostly depends on these indirect factors. Fig.7 shows the recovery curves of container cargo demands formulated by Table 4 and the relation between the operating ratio and the container cargo demands. These curves are formulated as follows:

$$
f(x)=a \cdot b^{\exp (-c \cdot x)}
$$

where $a, b$, and $c$ are the parameters given by Table 5. By using these curves, the container cargo demand in each municipality can be easily estimated, based on the earthquake and tsunami estimation published by the state or a local government. As for the seismic intensity 7, the curve was formulated by the data of ref. 9) separately, because the authors could not get the questionnaire data of the establishment that suffered the JMA seismic intensity scale of 7 .

In this study, the authors used the JMA seismic intensity scale, which is the most popular index of earthquake motion strength in Japan. For reference in the case of foreign countries, the relationships be tween the JMA intensity, and PGA (Peak Ground Acceleration), SI (Spectrum Intensity), and MMI 
Table 4 Average operating ratios of establishments after the Great East Japan Earthquake.

\begin{tabular}{|c|c|c|c|c|c|c|c|c|}
\hline \multicolumn{2}{|c|}{ Elap sed Days } & Immediately & 1 Week & 2 Weeks & 1 Month & 3 Months & 6 Months & 10 Months \\
\hline Tsunami & $\geq 2 \mathrm{~m}$ & $0 \%$ & $0 \%$ & $3 \%$ & $8 \%$ & $18 \%$ & $47 \%$ & $65 \%$ \\
Inundation & $<2 \mathrm{~m}$ & $0 \%$ & $4 \%$ & $11 \%$ & $34 \%$ & $60 \%$ & $83 \%$ & $90 \%$ \\
\hline & $6+$ & $9 \%$ & $18 \%$ & $34 \%$ & $59 \%$ & $82 \%$ & $88 \%$ & $93 \%$ \\
JMA & $6-$ & $12 \%$ & $19 \%$ & $36 \%$ & $62 \%$ & $86 \%$ & $92 \%$ & $92 \%$ \\
Seismic & $5+$ & $27 \%$ & $35 \%$ & $55 \%$ & $75 \%$ & $91 \%$ & $95 \%$ & $96 \%$ \\
Intensity & $5-$ & $52 \%$ & $62 \%$ & $71 \%$ & $84 \%$ & $93 \%$ & $97 \%$ & $95 \%$ \\
& 4 & $60 \%$ & $64 \%$ & $72 \%$ & $85 \%$ & $94 \%$ & $97 \%$ & $95 \%$ \\
\hline
\end{tabular}

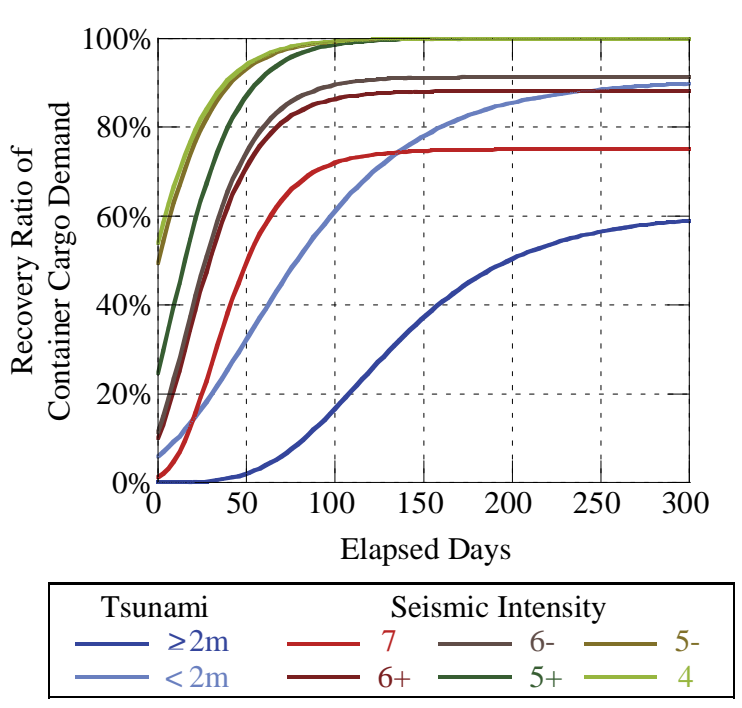

Fig.7 Recovery carve of container cargo demand.

Table 5 Parameters for recovery curve.

\begin{tabular}{|c|c|c|c|c|}
\hline \multicolumn{2}{|c|}{$\begin{array}{c}\text { Strength } \\
\text { of Hazard }\end{array}$} & \multicolumn{3}{c|}{ Parameter } \\
\cline { 2 - 5 } & $a$ & $b$ & $c$ \\
\hline Tsunami & $\geq 2 \mathrm{~m}$ & 60.6 & 0.000121 & 0.0194 \\
Inundation & $<2 \mathrm{~m}$ & 90.5 & 0.0652 & \\
\hline & 7 & 75.0 & 0.015 & \\
JM A & $6+$ & 88.3 & 0.112 & \\
Seisimic & $6-$ & 91.4 & 0.125 & \multirow{2}{*}{0.046} \\
Intensity & $5^{+}$ & 100.0 & 0.247 & \\
& $5-$ & 100.0 & 0.495 & \\
& 4 & 100.0 & 0.539 & \\
\hline
\end{tabular}

(Modified Mercalli Intensity) are shown in Table 6, which was prepared by Karim and Yamazaki ${ }^{15)}$ and Worden et al. ${ }^{16)}$. Among these relationships, those between MMI and JMA intensity is relatively weak because MMI is converted from JMA intensity through PGA, not directly.

The estimation procedure using the recovery curves of Fig.7 is as follows:

i) grasping the geographical location of container cargo owners;

ii) assessing the hazard strength (seismic intensity and tsunami inundation depth) of each municipality.

Table 7 demonstrates a case study of the Sendai-Shiogama port in the aftermath of the Great East Japan Earthquake. In the table, the column "Container Throughput" includes the ratio of the container
Table 6 Relation between seismic intensity scale.

\begin{tabular}{|c|r|r|r|}
\hline $\mathrm{I}_{\mathrm{JMA}}$ & PGA $\left(\mathrm{cm} / \mathrm{s}^{2}\right)$ & SI $(\mathrm{cm} / \mathrm{s})$ & MMI \\
\hline 4 & 73 & 6.9 & 5.3 \\
$5-$ & 189 & 16.9 & 6.8 \\
$5^{+}$ & 357 & 30.9 & 7.8 \\
$6-$ & 674 & 56.2 & 8.9 \\
$6+$ & 1,273 & 102.4 & 9.9 \\
7 & 3,306 & 251.8 & 11.4 \\
\hline
\end{tabular}
* PGA \& SI: Calculated by formula in ref. 15)
MMI: Calculated by formula in ref. 15) \& 16)

cargo throughputs of each municipality, arranged by the data of the investigation of the nationwide import/export container cargo flow ${ }^{17)}$. In addition, "Tsunami Inundation/JMA Seismic Intensity" is the ratio of the number of establishments in each municipality. Finally, the container cargo demand is calculated by multiplying "Container Throughput" by the recovery ratio of container cargo demand of each hazard ("Tsunami Inundation/JMA Seismic Intensity”) in Fig.7.

\section{(3) Estimation of ferry cargo demand}

As to the ferry cargo demand, a decrease in demand was hardly seen at the Great East Japan Earthquake; the first request for deployment of the Self-Defense Force was made only after six minutes from the outbreak of the earthquake, and the extra ferry services for dispatching began on the next day. The ordinary services also recovered within two weeks mostly by using alternative ports; this recovery pace is much faster than that of container demand in Fig. 7. The reasons for this are: i) the domestic ferry cargos normally include commodities that are less affected by disaster; therefore, are considered to maintain constant transportation demand; ii) some cargo handling demands increased due to emergency supply demand to the affected area in the aftermath of the disaster.

Table 8 shows the ratio of cargo commodities of the ferry cargo in comparison with that of the inter national container cargo. Over half of the cargo of the international container cargo is shared by the heavy industries such as "Metal \& Machine Industry" and "Chemical Industry," while that of ferry cargo is largely shared by the commodity that is not affected 
Table 7 Procedure for estimating container cargo demand (Sendai-Shiogama port).

\begin{tabular}{|c|c|c|c|c|c|c|c|c|c|c|}
\hline \multirow{2}{*}{ Municipality } & \multicolumn{2}{|c|}{ Container Throughput } & \multicolumn{8}{|c|}{ Tsunami Inundation / JM A Seismic Intensity } \\
\hline & Ton & Ratio & $\geq 2 \mathrm{~m}$ & $<2 \mathrm{~m}$ & 7 & $6+$ & 6- & $5+$ & $5-$ & 4 \\
\hline Iwanuma City & 55,968 & $49.0 \%$ & $29 \%$ & $29 \%$ & - & - & $43 \%$ & - & - & - \\
\hline Miyagino Ward, Sendai City & 23,750 & $20.8 \%$ & $33 \%$ & $19 \%$ & - & $40 \%$ & $7 \%$ & - & - & - \\
\hline Ishinomaki City & 11,876 & $10.4 \%$ & $88 \%$ & $8 \%$ & - & - & $4 \%$ & - & - & - \\
\hline Hirosaki City & 7,639 & $6.7 \%$ & - & - & - & - & - & - & - & $100 \%$ \\
\hline Wakabayashi Ward, Sendai City & 4,829 & $4.2 \%$ & - & - & - & $72 \%$ & $28 \%$ & - & - & - \\
\hline Kitakami City & 3,342 & $2.9 \%$ & - & - & - & - & $11 \%$ & $89 \%$ & - & - \\
\hline Tagajo City & 2,732 & $2.4 \%$ & $50 \%$ & $50 \%$ & - & - & - & - & - & - \\
\hline Natori City & 2,253 & $2.0 \%$ & - & - & - & - & $100 \%$ & - & - & - \\
\hline Shiogama City & 1,762 & $1.5 \%$ & $31 \%$ & $46 \%$ & - & - & $23 \%$ & - & - & - \\
\hline
\end{tabular}

Table 8 Commodity of container \& ferry cargo.

\begin{tabular}{|l|r|r|}
\hline \multicolumn{1}{|c|}{ Commodity of Cargo } & Container & Ferry \\
\hline Agricultural Products & $4.8 \%$ & $12.8 \%$ \\
Forest Products & $2.6 \%$ & $2.9 \%$ \\
Mineral Products & $1.5 \%$ & $0.7 \%$ \\
Metal \& Machine Industry & $36.0 \%$ & $21.9 \%$ \\
Chemical Industry & $14.1 \%$ & $9.3 \%$ \\
Light Industry & $9.6 \%$ & $20.0 \%$ \\
Miscellaneous Industry & $23.1 \%$ & $7.7 \%$ \\
Recy cle Products, Waste & $8.4 \%$ & $23.6 \%$ \\
\hline
\end{tabular} *Container: Data of the international container cargos
from ref. 17). The contents of the coastal container
cargos are almost the same.
**Ferry: Data from ref. 18)

by the depression in the operating ratio of establishments such as "Agricultural Products," "Light Industry,” and "Recycle Products, Waste.” In Japan, the major part of the coastal container cargo is the feeder transportation of the international container cargo.

As to the increase in cargo demand, some bulky emergency supplies, and dispatched search and rescue parties of the Self-Defense Forces, police department and fire department were transported by ferry in the aftermath of the Great East Japan Earthquake. Approximately 60,000 personnel and 166,000 vehicles were transported by ferries until four months after the earthquake ${ }^{19)}$. In the aftermath of the Great Hanshin-Awaji Earthquake, ferry transport functioned as a substitute for land transport, because the railways and roads suffered severe damage. The ferry services at the earthquake-stricken Kobe port increased up to 18 and transported approximately 800,000 people, while the number of ferry services had been 7 before the earthquake ${ }^{20)}$. Although these transportation demands do not exist in ordinary time, the utilization of ferry transport, which does not need cargo handling facilities at port, was already assumed at a Nankai Trough Earthquake $^{21)}$ and has been assumed at the other earthquakes. As described above, the ferry transport demand hardly decreases in total in the aftermath of disasters.

\section{CONCLUSION}

This study discussed the methodologies for estimating port cargo demands in the aftermath of large-scale earthquakes and tsunamis. As a result, practical estimation methods were recommended for each cargo type, as the authors' contribution.

At first, the authors noted that demand estimation was essential for developing and implementing the business continuity plans at ports, for which port user perspective was of great significance. In this regard, it was concluded that questionnaire/interview survey and inventory analysis could provide a practical approach for estimating possible port cargo handling demands of tramper service cargos such as dry/liquid bulk cargo and complete cars, which involve a limited number of cargo owners. Specific examples were given in this regard to demonstrate the suggested methods.

On the other hand, statistical approaches were identified to be effective for the estimation of liner service cargos such as container and ferry transport in the disaster-stricken ports. The authors provided, based on statistical approaches, recovery curves for estimating container cargo demand at ports. Ferry cargo demand in the aftermath of the Great East Japan Earthquake was also reviewed and discussed.

The authors believe that the above discussions may pave the way to further sophisticated methodologies for port-BCP preparation, and will undertake research activities in this area to further contribute to achieving a resilient global maritime transportation network.

\section{REFERENCES}

1) Nakajima, I., Okabe, S., Watanabe, K. and Sakurai, M. : ISO22301 : 2012 Business Continuity Management System Explanation of Requirement, Japan Standards Association, 2013.

2) Mansouri, M., Nilchiani, R. and Mostashari, A. : A policy making framework for resilient port infrastructure systems, Marine Policy, Vol. 34, pp.1125-1134, 2010.

3) Miyamoto, T. and Arai, Y. : Proposal of measures for con- 
tinuity of port international distribution service in case of earthquake, Journal of Coastal Zone Studies, Vol. 22, No.4, pp.93-104, 2010.

4) Berle, O., Rice Jr., J. B. and Asbjorslett, B. R. : Failure modes in the maritime transportation system - a functional approach to throughput vulnerability, Maritime Policy and Management, Vol.38, No.6, pp.605-632, 2011.

5) Omer, M., Mostashari, A., Nilchiani, R. and Mansouri, M. : A framework for assessing resiliency of maritime transportation systems, Maritime Policy and Management, Vol.39, No.7, pp.685-703, 2012.

6) Abe, T. : An examination on the measures for resiliency of port logistics services after large-scale earthquakes, Proceedings of International Association of Maritime Economists Conference 2013, Paper ID: 20, 2013.

7) Trepte, K. and Rice Jr., J. B. : An initial exploration of port capacity bottlenecks in the USA port system and the implications on resilience, International Journal Shipping and Transport Logistics, Vol.6, No.3, pp.339-355, 2014.

8) Novati, M., Achurra-Gonzalez, P., Foulser-Piggott, R., Bowman, G., Bell, M. G. H. and Angeloudis, P. : Modelling the effects of port disruptions: assessment of disaster impacts using a cost-based container flow assignment in liner shipping networks, Transportation Research Board 94th Annual Meeting Compendium of Papers, 2014.

9) Nakano, K., Kajitani, Y. and Tatano, H. : Functional fragility curves for a production facility of industrial sectors in case of earthquake disaster, Journal of JSCE Ser. A1, Vol. 69, No.1, pp.57-68, 2013.

10) Akakura, Y., Henmi, M., Ono, K., Ishihara, M. and Fukumoto, M. : An estimation of recovery curve of maritime containerized cargo demand after large-scale earthquake and tsunami, Journal of JSCE Ser. D3, Vol. 70, No.5, pp.I_689-I_699, 2014.

11) Consultative Meeting for Business Continuity of Sakata Port : BCP of Sakata Port, 2015.

12) Masui, T. and Okamoto, H. : Initiative of business conti- nuity plan at Kanazawa port, Symposium on Project by Hokuriku Regional Development Bureau, 2013.

13) Kochi Prefecture : Report of the Countermeasure for Long-Term Inundation caused by Nankai Trough Earthquake, 2013.

14) Council for Business Continuity of Kochi Port : Guideline of Business Continuity of Kochi Port, 2015.

15) Karim, K. R. and Yamazaki, F. : Correlation of JMA instrumental seismic intensity with strong motion parameters, Earthquake Engineering and Structural Dynamics 2002, Vol.31, pp.1191-1212, 2002.

16) Worden, C. B., Gerstenberger, M. C., Rhoades, D. A. and Wald, D. J. : Probabilistic relationships between ground -motion parameters and modified mercalli intensity in California, Bulletin of the Seismological Society of America, Vol.102, No.1, pp.204-221, 2012.

17) Ministry of Land, Infrastructure, Transport and Tourism : Nationwide Export/Import Container Transportation Survey, FY2013.

18) Ministry of Land, Infrastructure, Transport and Tourism : Domestic Unitload Transport Survey, FY2012.

19) Tatsumi, J. : Activity of Ferry Transport at the Great East Japan Earthquake, Council for the Countermeasure against Earthquake and Tsunami at Shikoku Port, 2011.

20) Takahashi, H., Nakamoto, T., Akakura, Y. and Yoshimura, H. : Analysis of transportation-modes after the $1995 \mathrm{Hy}-$ ogoken-Nanbu Earthquake, The 10th Earthquake Engineering Symposium Proceedings, Vol.10-3, pp.3125-3130, 1998.

21) Ono, K., Tatsumi, J., Nakao, T. and Shimakura, Y. : Possible mobilization of ferry boats for facilitating seamless logistics at the disaster area, Journal of Coastal Zone Studies, Vol.28, No.1, pp.71-82, 2015.

(Received July 1, 2016) 